\title{
Correction to: The effect of glutamine supplementation on serum levels of some inflammatory factors, oxidative stress, and appetite in COVID-19 patients: a case-control study
}

\author{
Mahsa Mohajeri $^{1,2}$ (D) Ehsan Horriatkhah ${ }^{1,3} \cdot$ Reza Mohajery $^{4}$
}

Published online: 20 December 2021

(c) Springer Nature Switzerland AG 2021

\section{Correction to: Inflammopharmacology https://doi.org/10.1007/s10787-021-00881-0}

There was a writing typo in Table 3. In fact, 38 of the 123 patients admitted to the ICU have died (30.89\%). This mortality rate was from 123 patients admitted to ICU.

Correction of the text in the section "Results" in line 16-17: There was a significant difference in mortality rates between the groups, 38 (30.89) deaths were observed in the control group.

Corrected Table 3:
Table 3 Duration of hospitalization, the necessity of intensive care unit, and mortality of the study groups after intervention

\begin{tabular}{llll}
\hline & Control group & Case group & $P^{*}$ \\
\hline $\begin{array}{l}\text { Duration of hospi- } \\
\text { talization }\end{array}$ & $14.3 \pm 5.3$ & $10.5 \pm 4.8$ & 0.015 \\
$\begin{array}{l}\text { Necessity of } \\
\text { intensive care } \\
\text { unit (\%) }\end{array}$ & $123(53.47 \%)$ & 0 & 0.008 \\
Mortality $^{\#}$ & $38(30.89 \%)$ & 0 & 0.029 \\
\hline
\end{tabular}

*Based on independents $t$-test and the significance level is less than 0.05

${ }^{\#}$ This mortality rate was from 123 patients admitted to ICU

Publisher's Note Springer Nature remains neutral with regard to jurisdictional claims in published maps and institutional affiliations.
The original article can be found online at https://doi.org/10.1007/ s10787-021-00881-0.

Mahsa Mohajeri

mahsa.mohajeri.93@gmail.com

1 Digestive Disease Research Center, Ardabil University of Medical Sciences, Ardabil, Iran

2 Academic Center for Education, Culture and Research, Ardabil, Iran

3 Tehran University of Medical Science, Tehran, Iran

4 Energy Management Research Center, University of Mohaghegh Ardabili, Ardabil, Iran 